\title{
Task Force on The Right to Effective Behavioral Treatment
}

\section{Executive Council Liaison Commentary}

Numerous controversies involving professional groups, advocacy organizations, the courts, state legislatures, and the media have arisen in recent years over issues related to behavioral treatment. Although individual members of the Association for Behavior Analysis (ABA) have played a significant role in resolving some of these questions, the Association has never adopted a policy or issued a formal statement on the nature and use of therapeutic techniques derived from the science of behavior. Therefore, the ABA Executive Council appointed a task force in May 1986 with a charge to consider treatment-related issues, with particular focus on clients' rights.

Chaired by Ron Van Houten, the Task Force on the Right to Effective Treatment met on several occasions, presented initial findings, and solicited feedback from ABA members in a symposium at the 1987 convention; prepared several draft documents; and submitted a final report to the Executive Council at its October 1987 meeting. The Council reviewed each draft and accepted the final report. Subsequently, the Task Force members submitted the report to the Editor of The Behavior Analyst, and it is contained on the following pages.

Although the Task Force report is based on input from a number of ABA members in addition to those on the Task Force and the Executive Council, acceptance by the Executive Council and publication in The Behavior Analyst do not imply that the report reflects the view of the majority of ABA members, nor do these actions establish any of the content as Association policy. At its May 1988 meeting, the ABA Executive Council recommended that an abbreviated version of the Task Force report be prepared and sent to all voting members of ABA. Upon majority approval, that version of the document will become official Association policy.

\author{
Brian A. Iwata \\ Executive Council Liaison \\ Task Force on the Right to \\ Effective Behavioral Treatment
}

